\title{
Hybrid Zinc-Based Multilayer Systems with Improved Protective Ability against Localized Corrosion Incorporating Polymer-Modified ZnO or CuO Particles
}

\author{
Nelly Boshkova, Kamelia Kamburova, Tsetska Radeva and Nikolai Boshkov *
}

check for updates

Citation: Boshkova, N.; Kamburova, K.; Radeva, T.; Boshkov, N. Hybrid Zinc-Based Multilayer Systems with Improved Protective Ability against Localized Corrosion Incorporating Polymer-Modified $\mathrm{ZnO}$ or $\mathrm{CuO}$ Particles. Coatings 2021, 11, 1223. https: / /doi.org/10.3390/ coatings11101223

Academic Editors: Alessandro Latini, Luigi Calabrese and Ingrid Milošev

Received: 25 August 2021

Accepted: 5 October 2021

Published: 8 October 2021

Publisher's Note: MDPI stays neutral with regard to jurisdictional claims in published maps and institutional affiliations.

Copyright: (c) 2021 by the authors. Licensee MDPI, Basel, Switzerland. This article is an open access article distributed under the terms and conditions of the Creative Commons Attribution (CC BY) license (https:// creativecommons.org/licenses/by/ $4.0 /)$.
Bulgarian Academy of Sciences, Institute of Physical Chemistry "Rostislaw Kaishev", Acad. G. Bonchev Street, bl. 11, 1113 Sofia, Bulgaria; nelly.boshkova@ipc.bas.bg (N.B.); kamelia@ipc.bas.bg (K.K.); radeva@ipc.bas.bg (T.R.) * Correspondence: NBoshkov@ipc.bas.bg

Abstract: Localized corrosion and biofouling cause very serious problems in the marine industries, often related to financial losses and environmental accidents. Aiming to minimize the abovementioned, two types of hybrid Zn-based protective coatings have been composed. They consist of a very thin underlayer of polymer-modified $\mathrm{ZnO}$ or $\mathrm{CuO}$ nanoparticles and toplayer of galvanic zinc with a thickness of $\sim 14 \mu \mathrm{m}$. In order to stabilize the suspensions of $\mathrm{CuO}$ or $\mathrm{ZnO}$, respectively, a cationic polyelectrolyte polyethylenimine (PEI) is used. The polymer-modified nanoparticles are electrodeposited on the steel (cathode) surface at very low cathodic current density and following $\mathrm{pH}$ values: $1 / \mathrm{CuO}$ at $\mathrm{pH} 9.0$, aiming to minimize the effect of aggregation in the suspension and dissolution of the $\mathrm{CuO}$ nanoparticles; $2 / \mathrm{ZnO}$ at $\mathrm{pH} 7.5$ due to the dissolution of $\mathrm{ZnO}$. Thereafter, ordinary zinc coating is electrodeposited on the $\mathrm{CuO}$ or $\mathrm{ZnO}$ coated low-carbon steel substrate from a zinc electrolyte at $\mathrm{pH}$ 4.5-5.0. The two-step approach described herein can be used for the preparation of hybrid coatings where preservation of particles functionality is required. The distribution of the nanoparticles on the steel surface and morphology of the hybrid coatings are studied by scanning electron microscopy. The thickness of the coatings is evaluated by a straight optical microscope and cross-sections. The protective properties of both systems are investigated in a model corrosive medium of $5 \% \mathrm{NaCl}$ solution by application of potentiodynamic polarization (PDP) curves, open circuit potential (OCP), cyclic voltammetry (CVA), and polarization resistance (Rp) measurements. The results obtained allow us to conclude that both hybrid coatings with embedded polymer-modified $\mathrm{CuO}$ or $\mathrm{ZnO}$ nanoparticles ensure enhanced corrosion resistance and protective ability compared to the ordinary zinc.

Keywords: hybrid coatings; corrosion; $\mathrm{CuO}$ and $\mathrm{ZnO}$ nanoparticles; polymeric modification

\section{Introduction}

Corrosion of metals, and, in particular, low-carbon steel, is a global problem that causes major economic, social, and environmental damage [1]. This phenomenon proceeds by different mechanisms and is of different types, some of which can be classified as very dangerous-local corrosion and biofouling. Local corrosion occurs in most cases practically imperceptible to the naked eye, penetrating deep inside the structure or equipment, while the damage is sudden and often with catastrophic consequences. Although corrosion protection is a subject of investigation by many research teams and laboratories, so far, no reliable methodology has been developed to prevent this event.

One of the most commonly used metals for corrosion protection of steel is zinc, as well as some zinc alloys thereof. Zinc coatings and alloys are known mainly as "sacrificial type" because zinc dissolves before iron during the corrosion attack and is more corrosionresistant at atmospheric conditions. The reason for this is the appearing surface layer of low soluble corrosion products (mainly oxides and hydroxides), the latter hindering the penetration of the aggressive environment deeply inside. 
One way to achieve better corrosion resistance is through the application of metallic or organic coatings [2], the latter acting as a barrier to aggressive agents. According to the scientific literature, the incorporation of selected nano- or micro-sized particles (silicates, oxides of various metals, carbon particles, etc.) improves the anticorrosion, "selfhealing", and mechanical indicators of the coatings [3-6]. The higher protective ability of steel substrates from localized corrosion can be obtained, for example, by application of polyaniline-based composite coatings [7] or by deposition/electrodeposition of a modified $\mathrm{ZnO}$ nanoparticles layer on their surface [8-14].

For example, polarization curves of $\mathrm{ZnO}$-alginate coated steel show a lower corrosion current compared to the bare steel. It seems that electrophoretic deposition of colloidal particles is a fast and efficient method for obtaining uniform coatings on metallic surfaces $[12,15,16]$. By altering the applied potential, deposition time, and composition of the suspension, it is possible to control the thickness and microstructure of the deposited coatings. Both aqueous and non-aqueous $\mathrm{ZnO}$ suspensions can be used for the preparation of coatings on metal surfaces. It is known that $\mathrm{ZnO}$ combines the surface properties of an oxide with a $\mathrm{pH}$-dependent charge density due to proton adsorption-desorption on $\mathrm{ZnOH}$ sites [17]. In addition, the $\mathrm{pH}$ value of the point of zero charge of these nanoparticles is at $\mathrm{pH}$ 9.4-9.6, i.e., they are positively charged below this $\mathrm{pH}$ and negatively charged above it $[18,19]$. The $\mathrm{pH}$ value of the solution strongly influences the particle size in the abovementioned $\mathrm{pH}$ regions where dissolution and aggregation ( $\mathrm{pH} 6.5$ and 9.4) occur [18].

It follows that one method to prepare stable $\mathrm{ZnO}$ suspension is to adjust the $\mathrm{pH}$ to regions with high electrostatic repulsion between the particles. Lowering the $\mathrm{pH}$ below 6.5 was found to increase the particles' charge, but the $\mathrm{ZnO}$ dissolved rapidly under acidic conditions. Another method for stabilization of particles suspension is surface modification using polyelectrolytes, which can control electrostatic (and steric) forces between particles.

Biofouling is another great problem, especially for marine structures, leading to increased fuel consumption of ships, as well as to microbiologically induced corrosion degradation. In order to minimize this process, the substrate can be treated with selected biocides [20-22]. It is expected that this action will lead to long-term protection against biocorrosion due to the controllable release of the biocide. To the best of our knowledge, copper-based coatings can be used as antifouling ones due to their toxicity to marine microorganisms [23-26]. According to [27], in the marine environment, the antifouling action of the copper-based coatings is realized through the release of cuprous and copper ions, the latter reacting with chlorine ones. It is also demonstrated that $\mathrm{CuO}$ nanoparticles may dissociate into $\mathrm{Cu}^{2+}$, and higher concentrations of these ions significantly affect the growth of aquatic microorganisms [28]. Some investigators claim that the dissolution of $\mathrm{CuO}$ nanoparticles depends on several factors such as particle size, shape and surface charge, and characteristics of the media ( $\mathrm{pH}$, ionic strength, dissolved organic matter) [29,30].

Keeping in mind the investigations of [30-32], one possible method to prepare a stable suspension (suitable for subsequent electrodeposition) of $\mathrm{CuO}$ nanoparticles is to adjust the $\mathrm{pH}$ to regions with high electrostatic repulsion between the latter. At acidic conditions, $\mathrm{CuO}$ nanoparticles are highly charged and stable. At the isoelectric point, they have practically no charge, and the repulsive forces between them weaken, which leads to unstable suspension. After the isoelectric point, the repulsive forces become stronger again, decreasing aggregation. Additionally, for suspension stabilization, surface modification of the particles with polyelectrolytes can be applied to control the electrostatic and steric forces.

According to [33], electrophoretic deposition seems to be an attractive technique offering a high deposition rate and obtaining relatively thick films. In addition, the control of the colloidal behavior of the nanoparticles plays a key role in preparing stable suspensions suitable for electrophoretic deposition. The general peculiarity is that the particles need to obtain a significant surface charge density in order to be well dispersed in the suspension.

The main idea of the present investigations is to show the processes of polymer modification of $\mathrm{ZnO}$ and $\mathrm{CuO}$ nanoparticles and their incorporation in a protective hybrid 
coating system as an underlayer followed by electrodeposition of ordinary $\mathrm{Zn}$ as a toplayer (in a two-step procedure). It is expected that the presence of $\mathrm{ZnO}$ or $\mathrm{CuO}$ nanoparticles will create an additional barrier between the zinc coating and the steel substrate, thus blocking (slowing down) the penetration of the corrosion medium deep inside and ensuring passive corrosion protection against localized corrosion and/or biofouling. The protective characteristics of the newly obtained systems are evaluated in a model corrosive medium by the application of potentiodynamic polarization (PDP) curves, open circuit potential $(\mathrm{OCP})$, cyclic voltammetry (CVA), and polarization resistance (Rp) measurements. In addition, a comparative conclusion about the protective characteristics concerning both hybrid coating systems and ordinary zinc in that model medium is completed.

\section{Materials and Methods}

\subsection{Materials and Preparation of Stable $\mathrm{ZnO}$ Suspension}

Commercially available ZnO nanoparticles (Sigma-Aldrich, Darmstadt, Germany, $<100 \mathrm{~nm}$ particle size) are applied. Poly(ethyleneimine) (PEI, $\left.\mathrm{M}_{\mathrm{w}}=25 \mathrm{kDa}\right)$ was also purchased from Sigma-Aldrich. This polyelectrolyte is selected aiming to improve the stability of $\mathrm{ZnO}$ suspension against aggregation and later to promote the nanoparticles' cathodic deposition on steel substrate by electrophoresis. PEI is charged in neutral and acidic solutions due to protonation of $-\mathrm{N}-,-\mathrm{NH}-$, or $-\mathrm{NH}_{2}$ groups.

Stable $\mathrm{ZnO}$ suspension is prepared and evaluated according to [34] $-0.1 \mathrm{~g} / \mathrm{L} \mathrm{ZnO}$ nanopowder is added to a $0.1 \mathrm{~g} / \mathrm{L}$ PEI aqueous solution. Thereafter, the so-obtained suspension is ultrasonicated for $10 \mathrm{~min}$ with the aim of improving the dispersion of $\mathrm{ZnO}$ nanoparticles. The $\mathrm{pH}$ value of the suspension at the beginning is $\sim 10$, but thereafter, this parameter decreases up to $\sim 7.5$ during the suspension dilution with water in order to achieve a concentration of $4 \times 10^{-2} \mathrm{~g} / \mathrm{L}$.

\subsection{Materials and Preparation of Stable $\mathrm{CuO}$ Suspension}

Commercially available $\mathrm{CuO}$ nanopowder (from Sigma-Aldrich, $<50 \mathrm{~nm}$ ) is used for the investigations. The stock suspension of $\mathrm{CuO}$ nanoparticles of concentration $1 \mathrm{~g} / \mathrm{L}$ is prepared by sonication in ice for $15 \mathrm{~min}$ while the working concentration is set to $4 \times 10^{-2} \mathrm{~g} / \mathrm{L}$ in order to ensure better quality for the follow-up experiments. The $\mathrm{CuO}$ nanopowder $(1 \mathrm{~g} / \mathrm{L})$ is added to a PEI aqueous solution $(1 \mathrm{~g} / \mathrm{L})$, and the suspension is ultrasonicated for $15 \mathrm{~min}$ to improve the $\mathrm{CuO}$ dispersion. The initial $\mathrm{pH}$ value of the suspension is $\sim 11$, but it decreases rapidly after dilution with water, reaching $~ 7.5$.

\subsection{Characterization of $\mathrm{ZnO}$ and $\mathrm{CuO}$ Nanoparticles}

Both types of nanoparticles are characterized in terms of their stability and particle size. A Dynamic Light Scattering (DLS ) particle sizer (Zetasizer Nano ZS, Malvern, Malvern Instruments Ltd., Worcestershire, UK) is used to measure their hydrodynamic diameter. A He-Ne laser is applied as a light source, and the intensity of the scattered light is measured by a detector at $173^{\circ}$. The intensity size distribution and the z-average diameter are obtained from the autocorrelation function. The electrophoretic mobilities $U_{e}$ of the nanoparticles are measured with a Mark 2 apparatus (Rank Brothers, Cambridge, UK) using a flat cell at room temperature. Their electrokinetic zeta potential $\zeta$ is calculated from the electrophoretic mobility by applying Smoluchowski equation $\zeta=4 \pi \eta \mathrm{U}_{\mathrm{e}} / \varepsilon$, where $\varepsilon$ is the electric permittivity and $\eta$ is the viscosity of the medium. Scanning Electron Microscopy (INCA Energy 350 unit, Oxford Instruments, Oxford, UK) is used for evaluation of the surface morphology of the samples obtained [34]. Cross-sections of both hybrid coatings are investigated with straight optical microscope Zeiss Axioscope 5 (ZEISS, Jena, Germany) magnification $\times 100$. 


\subsection{Electrodeposition of Hybrid Coatings Containing $\mathrm{ZnO}$}

The proposed hybrid coatings are obtained on low-carbon steel samples with working area of $6 \mathrm{~cm}^{2}$ (sizes $3 \mathrm{~cm} \times 1 \mathrm{~cm} \times 0.1 \mathrm{~cm}$ ) and prepared by two-step electrodeposition in the following way:

(1) First step is to electrodeposit a layer of PEI coated $\mathrm{ZnO}$ nanoparticles on low-carbon steel sample at $\mathrm{pH} 7.5$ (to minimize the $\mathrm{ZnO}$ solubility effects) at a cathodic current (direct current-DC) density of $0.02 \mathrm{~A} / \mathrm{dm}^{2}$ and application of non-soluble anodes. The duration of this step is $10 \mathrm{~min}$. As already discussed, the role of PEI is to provide large electrostatic repulsive forces between the positively charged $\mathrm{ZnO}$ nanoparticles stabilizing in such a way that the $\mathrm{ZnO}$ suspension is promoting their further electrodeposition on the cathode.

(2) Second step is to electrodeposit zinc coating (thickness $\sim 14 \mu \mathrm{m}$ ) on the obtained $\mathrm{ZnO}$ nanoparticles layer from slightly acidic zinc electrolyte $(\mathrm{pH} 4.5-5.0)$ at a cathodic current (direct current-DC) density of $2 \mathrm{~A} / \mathrm{dm}^{2}$ by using soluble zinc anodes. The duration of this step is $20 \mathrm{~min}$.

The electrolyte for obtaining ordinary zinc coating consists of $150 \mathrm{~g} / \mathrm{L} \mathrm{ZnSO} 4 \cdot 7 \mathrm{H}_{2} \mathrm{O}$, $30 \mathrm{~g} / \mathrm{L} \mathrm{NH}_{4} \mathrm{Cl}$, and $30 \mathrm{~g} / \mathrm{L} \mathrm{H}_{3} \mathrm{BO}_{3}$.

\subsection{Electrodeposition of Hybrid Coatings Containing $\mathrm{CuO}$}

The procedure is identical to the previous one-first, a layer of PEI coated $\mathrm{CuO}$ nanoparticles are electrodeposited on steel substrate at $\mathrm{pH} 9.0$ (to minimize the $\mathrm{CuO}$ solubility and aggregation effects) at a cathodic current (direct current-DC) density of $0.02 \mathrm{~A} / \mathrm{dm}^{2}$ and application of non-soluble anodes. Second step is the electrodeposition of zinc (thickness $\sim 14 \mu \mathrm{m}$ ) from the same electrolyte and the same conditions. The duration of the first and second steps is the same-10 min for Step 1 and 20 min for Step 2.

\subsection{Corrosion Characterization}

The characterization of the newly obtained hybrid coatings compared to the ordinary zinc in terms of the protective properties and corrosion behavior is realized by applying the following electrochemical methods-potentiodynamic (PDP) polarization, polarization resistance (Rp), open circuit potential (OCP), and cyclic voltammetry (CVA).

The protective ability of the galvanic and other coating types can be evaluated by application of the polarization resistance $(\mathrm{Rp})$ method. The value of this parameter is known to be inversely proportional compared to the value of the corrosion current, which follows from the frequently used equation of Stern and Gerry conserning the electrochemical polarization The measurements are realized in tri-electrode electrochemical glass cell with a volume of $300 \mathrm{~mL}$ (working electrode is the coating; reference electrode is Saturated Calomel Electrode; counter electrode is a platinum wire) with a scan rate of $1 \mathrm{mV} / \mathrm{s}$. According to the abovementioned equation, higher $\mathrm{Rp}$ values are an indicator for better protective ability and lower corrosion rate as well. The corrosion resistance (as well as the protective ability) of the coatings are estimated with "Corrovit" device (Producer "Tacussel", Villeurbanne, France). The standard deviation of the experimental results obtained is in the range of about $10 \%$.

Potentiodynamic polarization (PDP) investigations are generally used for accelerated characterization of the corrosion behavior of the coatings at conditions of external polarization. The same tri-electrode electrochemical cell, reference electrode, and counter electrode described above are used for these investigations. Potential range is between -1.2 and $0.4 \mathrm{~V}$, and scan rate is $1 \mathrm{mV} \cdot \mathrm{s}^{-1}$. VersaStat 4 unit (Princeton Applied Research, Oak Ridge, TN, USA) is the electrochemical workstation used. The testing of the samples is realized after preliminary temporizing during $15 \mathrm{~min}$ period in the model medium. The potentiodynamic scan initially starts from the cathodic area $(-100 \mathrm{mV}$ negative from the corrosion potential). Thereafter, the polarization passes through the corrosion potential zone, reaching the anodic area where the dissolution process occurs. The standard deviation of the experimental results obtained is in the range of about $10 \%$. 
PDP curves are stopped after visual appearance of the steel substrate is checked by "naked eye". The OCP and the Rp measurements are carried out for a prolonged interval of 25 days. CVA tests are carried out in the potential interval between -1.9 and $0.2 \mathrm{~V}$ with a scan rate of $10 \mathrm{mV} / \mathrm{s}$. More information about the principles and features of the methods used are described elsewhere [34,35].

\subsection{Corrosive Medium}

Electrochemical corrosion tests are performed at ambient temperature in a model corrosive medium of $5 \% \mathrm{NaCl}$ solution with $\mathrm{pH}$ value of $\sim 6.7$.

\subsection{Reproducibility}

The results from the investigations are based on average of 5 samples per type and per stage for initial and follow-up measurements.

\section{Results and Discussion}

\subsection{Characterization of ZnO Nanoparticles Dispersion}

The dispersion of $\mathrm{ZnO}$ nanoparticles in water leads to a self-adjusting $\mathrm{pH}$ of 7.5 and a zeta potential of $25 \mathrm{mV}$. This is below $30 \mathrm{mV}$, which is accepted as the minimum zeta-potential for electrostatically stabilized suspensions. However, the adsorption of $\mathrm{PEI}$ increases the zeta-potential value of the polymer-covered $\mathrm{ZnO}$ nanoparticles to about $50 \mathrm{mV}$, which is high enough to provide stabilization of the suspension. The $\mathrm{pH}$ of the suspension remains stable for $72 \mathrm{~h}$ after its dilution to a concentration of $4 \times 10^{-2} \mathrm{~g} / \mathrm{L}$ ( $\mathrm{pH}$ 7.5). More information concerning the characterization of $\mathrm{ZnO}$ nanoparticles is presented elsewhere [34].

\subsection{Characterization of $\mathrm{CuO}$ Nanoparticles}

The stabilization of the $\mathrm{CuO}$ nanoparticles with PEI is conducted at $\mathrm{pH} 9.5$, aiming at minimizing the undesirable effects. The zeta potential of the $\mathrm{CuO}$ nanoparticles increases after the addition of PEI. The particles exhibit a positive charge: the zeta potential increases from $+50 \mathrm{mV}$ for bare $\mathrm{CuO}$ nanoparticles at acidic conditions up to $+58 \mathrm{mV}$ in the presence of PEI, slightly decreasing at $\mathrm{pH} 7.0-9.5$ and more strongly at $\mathrm{pH} 11.0$. The zeta potential of $\mathrm{CuO}$ nanoparticles at the isoelectric point ( $\mathrm{pH}$ 9.5) is high enough after the adsorption of PEI to minimize the aggregation in the suspension. According to zeta potential measurements, $\mathrm{CuO}$ nanoparticles have a positive charge at $\mathrm{pH}$ values below the isoelectric point, and the PEI chains are positively charged as well [32]. The latter authors found the best stabilization conditions at $\mathrm{pH} 3$ and $\mathrm{pH} 9$. At $\mathrm{pH} 3$, fully protonated amine groups $\left[-\left(\mathrm{NH}_{3}\right)^{+}\right]$of the PEI repel each other, while the un-protonated amine groups form weak dative bonds with the $\mathrm{Cu}^{2+}$ ions on the surface. At $\mathrm{pH} 9$, stronger dative bonds are formed between the $\mathrm{Cu}^{2+}$ ions on the surface and the unprotonated amine groups. At both $\mathrm{pH}$ values, the mechanism of stabilization was characterized as electro-steric repulsion [32].

The main conclusion from the above experiments is that the nanoparticles in both suspensions are stabilized against aggregation (zeta-potential of the particles increase to about $50 \mathrm{mV}$ due to the polyelectrolyte adsorption), which is of importance for obtaining layers containing well-dispersed oxide particles of low solubility at $\mathrm{pH}$ of the suspensions close to their isoelectric points.

\subsection{Surface Morphology and Cross-Sections}

Figure 1 shows typical Scanning Electron Microscopy (SEM) micrographs of layers prepared by electrodeposition of A/. ZnO nanoparticles covered with PEI on steel surface; $\mathrm{B} /$. ZnO nanoparticles covered with PEI, followed by electrodeposition of ordinary zinc coating at $\mathrm{pH}$ 4.5-5.0. The microstructure of the coatings shows a nearly homogeneous distribution of the particles [34]. 


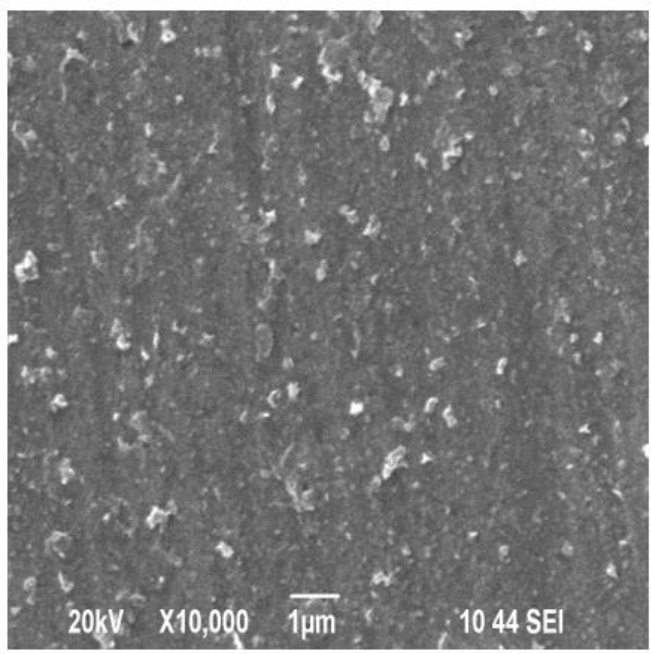

(A)

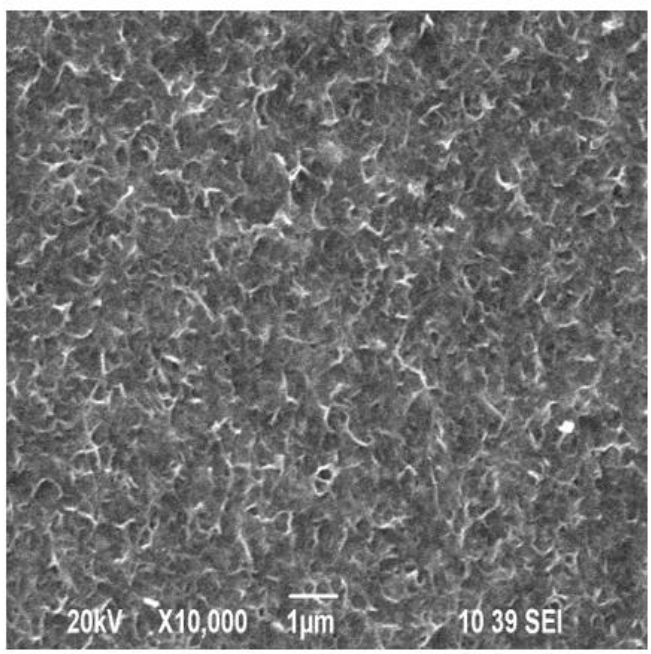

(B)

Figure 1. SEM micrographs of hybrid ZnO-containing coatings: (A) ZnO nanoparticles before electrodeposition of ordinary zinc; (B) final coating after zinc electrodeposition.

It is obvious that a small number of microscopic pores also appear on the surface, probably caused by water electrolysis during deposition of the $\mathrm{ZnO}$ nanoparticles, according to [14]. In addition, it seems that some of the $\mathrm{ZnO}$ nanoparticles appear on the surface of the final coating, most likely as a result of their detachment from the steel substrate and the displacement during the zinc electrodeposition.

Figure 2 presents SEM micrographs of $\mathrm{CuO}$ nanoparticles coated with PEI after deposition on steel substrate from a suspension with a concentration of $4 \times 10^{-2} \mathrm{~g} / \mathrm{L}$ at $\mathrm{pH} 9.0$ (Figure 2A). It seems that most of the electrodeposited particles have a size close to that of the primer dry $\mathrm{CuO}$ nanoparticles (less than $50 \mathrm{~nm}$ ). The surface morphology of the hybrid zinc coating with incorporated $\mathrm{CuO}$ nanoparticles is demonstrated in Figure 2B. Both micrographs show the formation of uniform zinc coatings on the steel substrate consisting of needle-like formations, most likely with metallic character (zinc compounds).

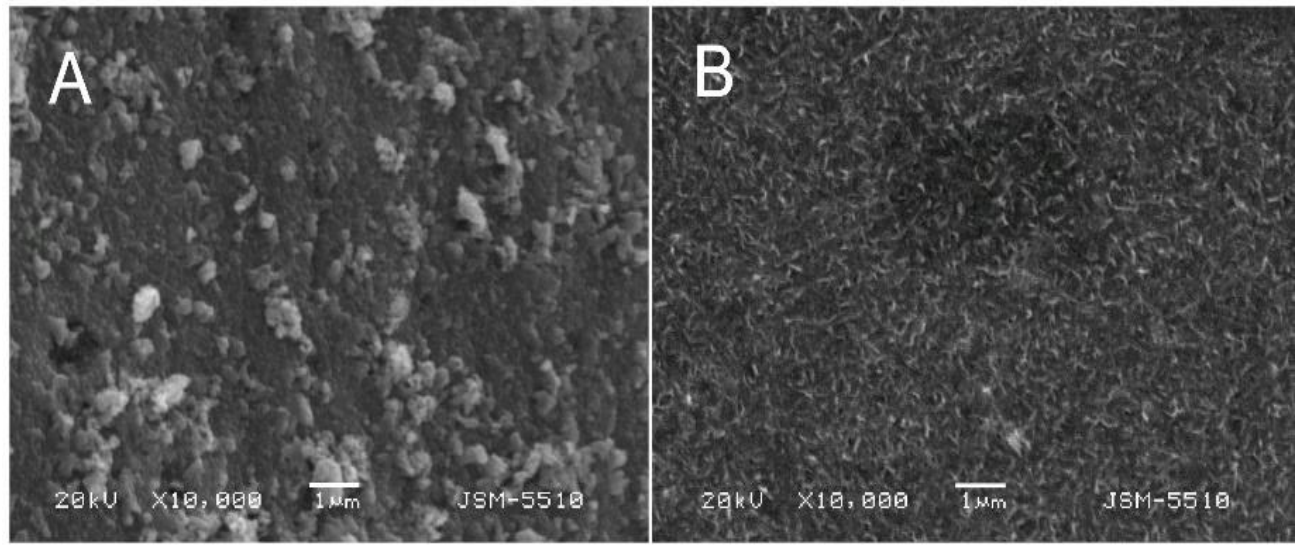

Figure 2. SEM micrographs of hybrid CuO-containing coatings: (A) CuO nanoparticles before electrodeposition of ordinary zinc; (B) final coating after zinc electrodeposition.

The cross-sections of both hybrid coatings are demonstrated in Figure 3. It is obvious that the thickness of the coatings is about $14 \mu \mathrm{m}$. The coatings are randomly thick through their length, and the border with the steel substrate is easily visible. A very thin layer most likely consisting of $\mathrm{ZnO}$ or $\mathrm{CuO}$ nanoparticles can be observed in that area. 

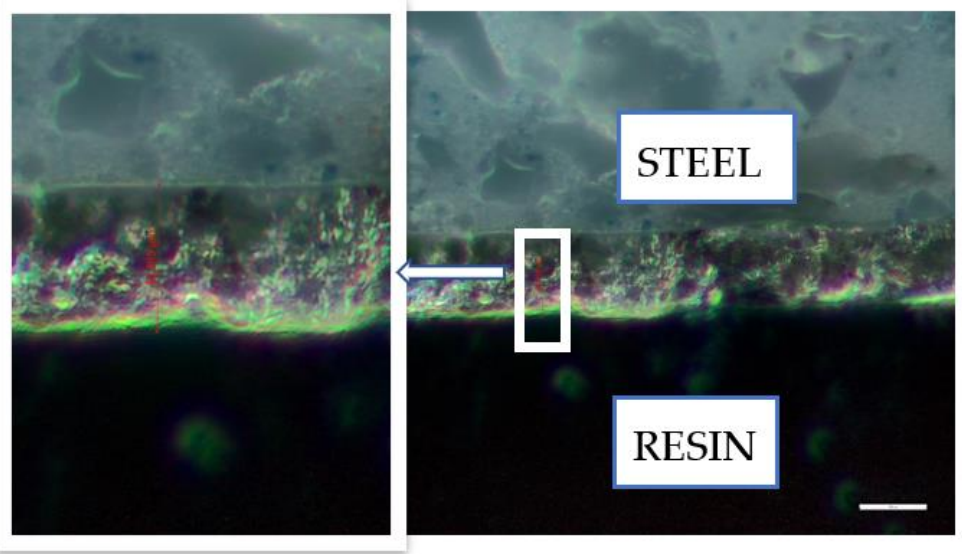

(A)
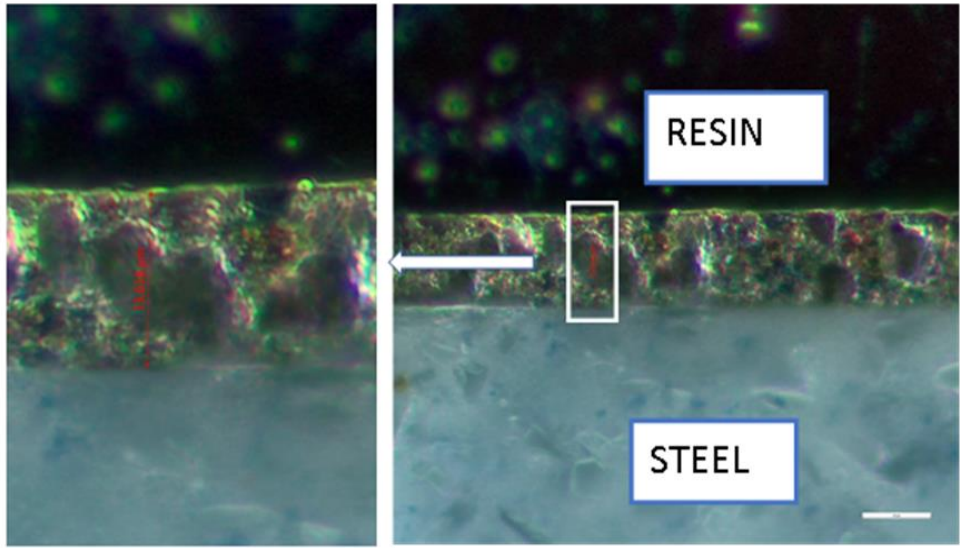

(B)

Figure 3. Cross-sections of hybrid $\mathrm{ZnO} / \mathrm{Zn}(\mathbf{A})$ and $\mathrm{CuO} / \mathrm{Zn}(\mathbf{B})$ hybrid coatings.

These investigations confirm, in general, the presence of the $\mathrm{ZnO}$ and $\mathrm{CuO}$ nanoparticles underlayer and the toplayer of ordinary zinc. The estimation mark (shown in white in the lower-right corner of the cross-section) is $10 \mu \mathrm{m}$.

\subsection{Polarization Resistance Measurements}

The experimental results obtained after polarization resistance measurements for a 25 days period of time are presented in Figure 4 . It is obvious that both hybrid coatings $\mathrm{ZnO} / \mathrm{Zn}$ and $\mathrm{CuO} / \mathrm{Zn}$ demonstrate higher Rp values, reaching $\sim 1240 \Omega \cdot \mathrm{cm}^{2}$ for $\mathrm{ZnO} / \mathrm{Zn}$ and $1120 \Omega \cdot \mathrm{cm}^{2}$ for $\mathrm{CuO} / \mathrm{Zn}$ at the end of the test. The Rp values of the ordinary zinc vary during the investigating period, reaching about $820 \Omega \cdot \mathrm{cm}^{2}$ on the twenty-fifth day. It can also be registered that the curve of $\mathrm{CuO} / \mathrm{Zn}$ shows an ever-increasing trend in contrast to the other samples. Finally, it can be summarized from these results that the newly developed hybrid coatings demonstrate better protective properties against the steel substrate compared to the ordinary zinc in a model medium containing $\mathrm{Cl}^{-}$ions as corrosion activators.

According to some previous investigations, the reason for such behavior of the hybrid coatings in a neutral corrosive medium is the appearance of a protective layer of zinc corrosion products $[35,36]$. In the case of hybrid systems, this layer is most likely mixed with the nanoparticles, especially after a prolonged time interval. This will lead to an additional physical barrier effect hindering the penetration of the corrosive agents $\left(\mathrm{Cl}^{-}\right.$ions) deep inside, demonstrating an additional protective function. This influence will be supported by the presence of some PEI amounts in the affected area, leading to a slowdown of the corrosion rate. The effect of PEI as a corrosion inhibitor in a $\mathrm{NaCl}$ aqueous solution 
has earlier been attributed to electrostatic interactions between PEI and the metal substrate, evidenced by X-ray photoelectron measurements [37].

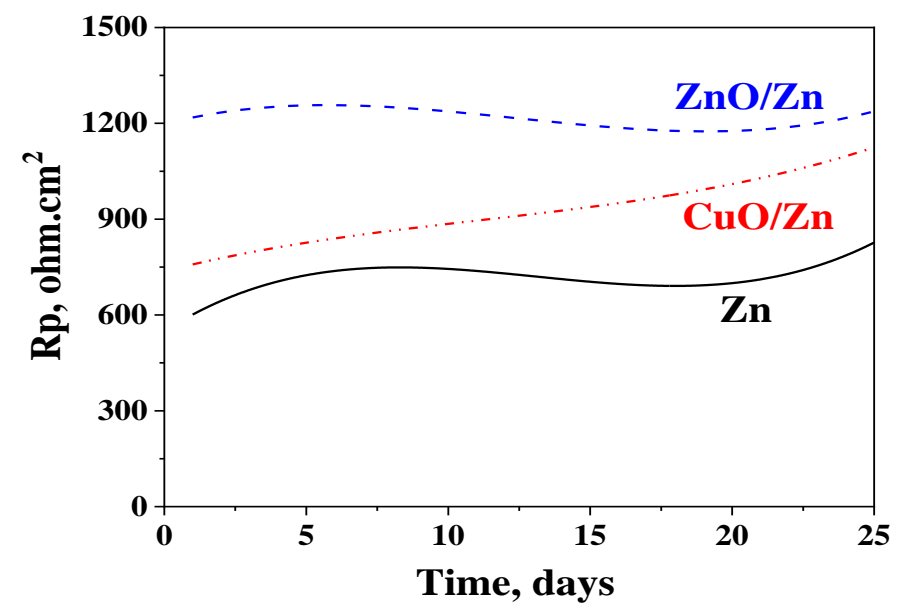

Figure 4. Polarization resistance (Rp) measurements of ordinary $\mathrm{Zn}$ and of both hybrid coatings in the model corrosive medium of $5 \% \mathrm{NaCl}$.

\subsection{Open Circuit Potential}

The experimental data from the OCP measurements during the test period for the investigated samples are presented in Figure 5. It can be registered that all the potentials are shifted in the positive direction from about $-1.08 \mathrm{~V}$ at the beginning of the measurement up to about $-1.03 \mathrm{~V}$ for $\mathrm{Zn}$ and hybrid $\mathrm{ZnO} / \mathrm{Zn}$ and about $-1 \mathrm{~V}$ for $\mathrm{CuO} / \mathrm{Zn}$ at the end. This observation can be explained by the fact that after 25 days, the corrosion process is penetrated deep inside the hybrid coating, most likely reaching the underlayer. In the case of $\mathrm{CuO} / \mathrm{Zn}$, the potential is more positive as a result of the appearance of some $\mathrm{CuO}$.

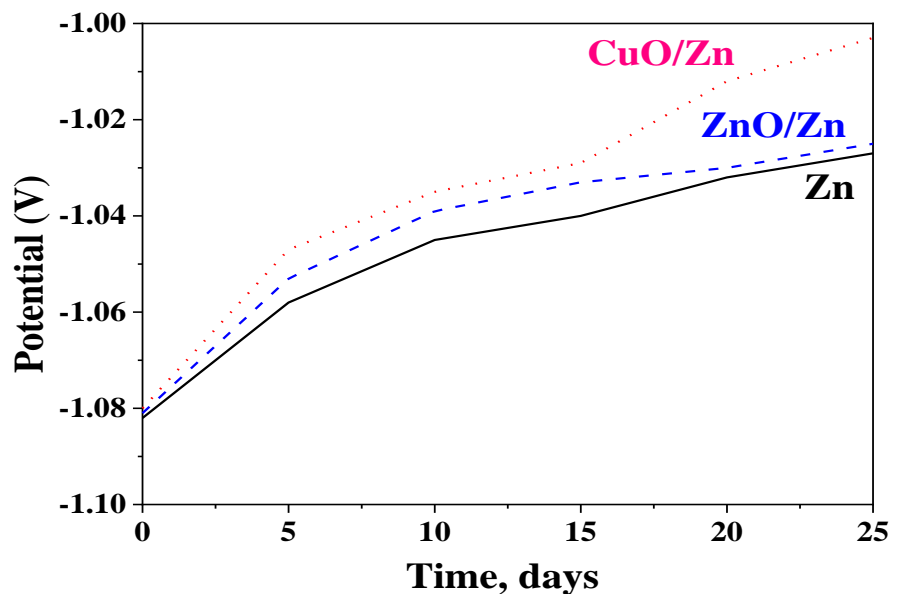

Figure 5. Open circuit potential (OCP) measurements of ordinary $\mathrm{Zn}$ and both hybrid coatings in the model corrosive medium of $5 \% \mathrm{NaCl}$.

\subsection{Polarization Resistance Measurements}

Figure 6 demonstrates the potentiodynamic polarization curves of the investigated coatings (as received). It can be seen that both hybrids have lower corrosion current densities compared to the ordinary zinc in that medium, and their corrosion potentials are shifted in the negative direction. This confirms their sacrificial nature, i.e., they will dissolve first in the case of corrosion attack, thus protecting the steel substrate to a higher degree. However, it must be noted that all three coating types are of "sacrificial type" and 
will protect (but with different efficiencies, the latter being greater for the hybrids) the steel substrate since the corrosion potential of the latter is about $-0.7 \mathrm{~V}$ in that medium.

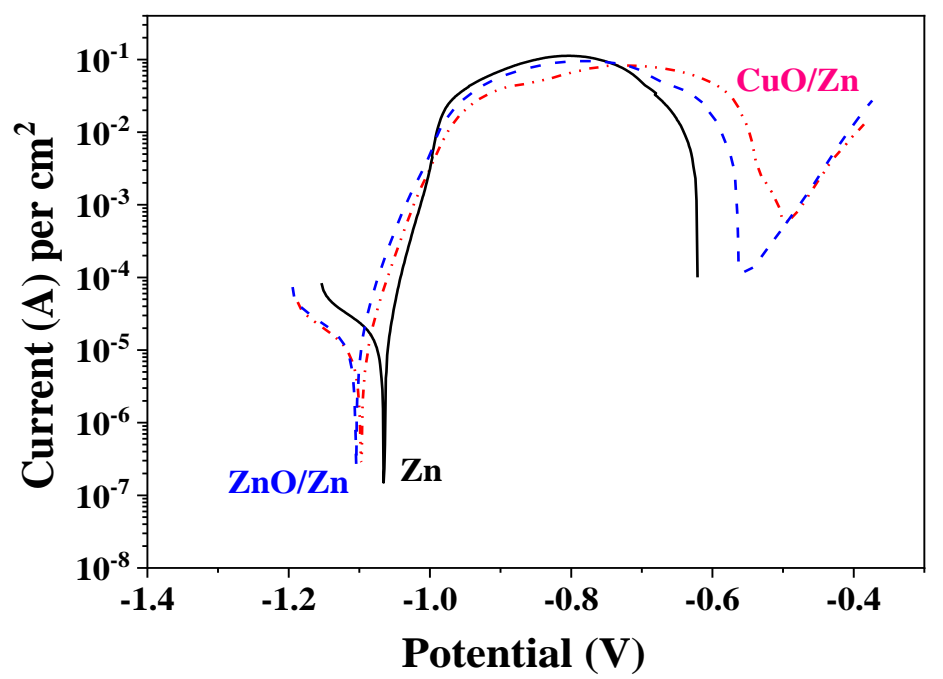

Figure 6. Potentiodynamic polarization measurements of ordinary $\mathrm{Zn}$ and both hybrid coatings in the model corrosive medium of $5 \% \mathrm{NaCl}$.

The most important electrochemical parameters obtained from this investigation are presented in Table 1.

Table 1. Some important electrochemical parameters obtained from the potentiodynamic polarization measurements (the presented values refer to a representative curve selected from investigations performed with a group of samples of a given species).

\begin{tabular}{cccc}
\hline Sample/Parameter & $\mathbf{I}_{\text {corr }}, \mathbf{A} \cdot \mathbf{c m}^{-2}$ & $\mathbf{E}_{\text {corr }}, \mathbf{V}$ & $\mathbf{I}_{\text {pass }}, \mathbf{A} \cdot \mathbf{c m}^{-\mathbf{2}}$ \\
\hline $\mathrm{CuO} / \mathrm{Zn}$ & $1.02 \times 10^{-5}$ & -1.094 & $6.3 \times 10^{-4}$ \\
$\mathrm{ZnO} / \mathrm{Zn}$ & $9.9 \times 10^{-6}$ & -1.104 & $1.3 \times 10^{-4}$ \\
$\mathrm{Zn}$ & $1.8 \times 10^{-5}$ & -1.065 & - \\
\hline
\end{tabular}

Aiming to obtain additional information about the corrosion behavior of all samples, the latter are the objects of potentiodynamic polarization investigations after 25 days of immersion in the model medium. The results are shown in Figure 7. It is obvious that the corrosion potential of the hybrid $\mathrm{ZnO} / \mathrm{Zn}$ is placed more negatively compared to the corrosion potential of the ordinary zinc. Contrary to this, the corrosion potential of $\mathrm{CuO} / \mathrm{Zn}$ is shifted strongly in the positive direction, becoming more noble. The most likely reason for this seems to be the appearance of $\mathrm{CuO}$ as a result of the corrosion process. In addition, it can be registered that the passivation area does not exist anymore for all the samples investigated. A possible reason for this result seems to be the partial dissolution of the systems, leading to appearing of some corrosion products with barrier properties but also to thinning of the protective layer in depth, and probably partial access of the corrosive agents to the substrate. 


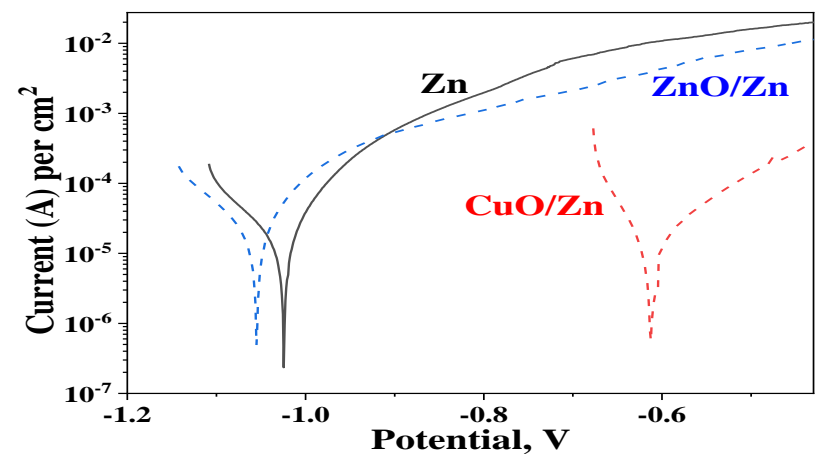

Figure 7. Potentiodynamic polarization measurements of $\mathrm{ZnO} / \mathrm{Zn}, \mathrm{CuO} / \mathrm{Zn}$, and ordinary $\mathrm{Zn}$ after 25 days' immersion in the model corrosive medium of $5 \% \mathrm{NaCl}$.

The electrochemical parameters are shown in Table 2.

Table 2. Some important electrochemical parameters obtained from the potentiodynamic polarization measurements after 25 days' immersion in the model corrosive medium (the presented values refer to a representative curve selected from investigations performed with a group of samples of a given species).

\begin{tabular}{ccc}
\hline Sample/Parameter & $\mathbf{I}_{\text {corr }}, \mathbf{A} \cdot \mathbf{c m}^{-2}$ & E $_{\text {corr, }} \mathbf{V}$ \\
\hline $\mathrm{CuO} / \mathrm{Zn}$ & $1.2 \times 10^{-5}$ & -0.612 \\
$\mathrm{ZnO} / \mathrm{Zn}$ & $1.3 \times 10^{-5}$ & -1.053 \\
$\mathrm{Zn}$ & $1.4 \times 10^{-5}$ & -1.024 \\
\hline
\end{tabular}

\subsection{Cyclic Voltammetry}

The experiments realized via this method are reported in Figure 8. They are carried out in the starting electrolytes (suspensions) for the electrodeposition of $\mathrm{ZnO}$ or $\mathrm{CuO}$ nanoparticles, respectively. It is obvious that the electrodeposition process of $\mathrm{ZnO}$ or $\mathrm{CuO}$ nanoparticle layers (which occurs at low current density) leads to a lower cathodic current rate- $1.5 \times 10^{-4} \mathrm{~A}$ for $\mathrm{ZnO}$ and $5.1 \times 10^{-4} \mathrm{~A}$ for $\mathrm{CuO}$, respectively. Both nanoparticle layers are electrodeposited with overvoltage compared to ordinary zinc (their deposition begins at more negative potentials); see the inset in Figure 8A.

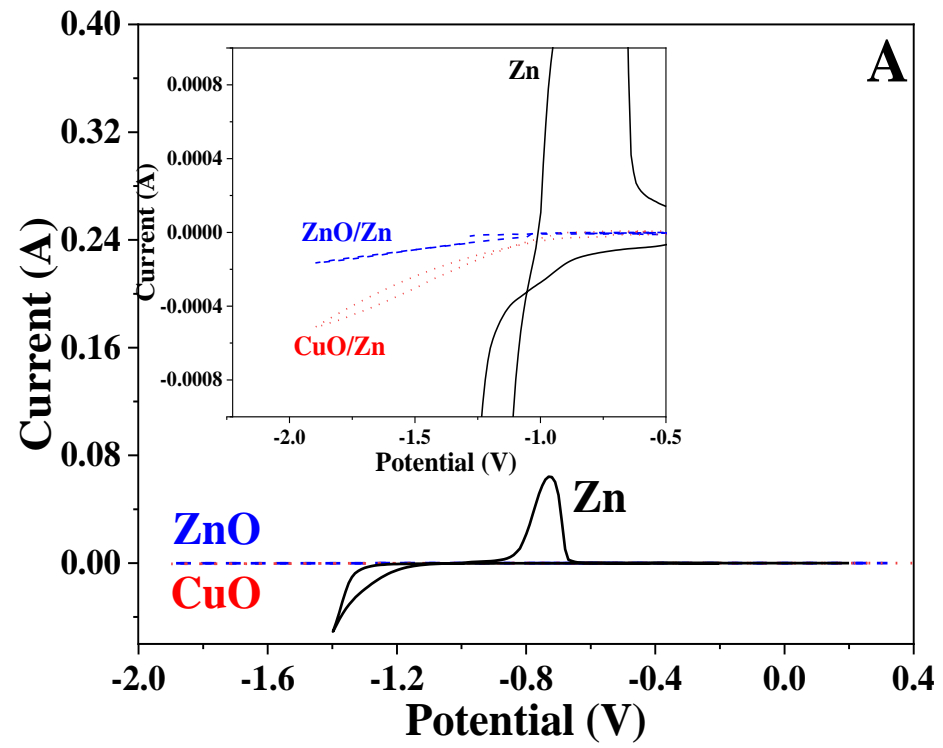

Figure 8. Cont. 


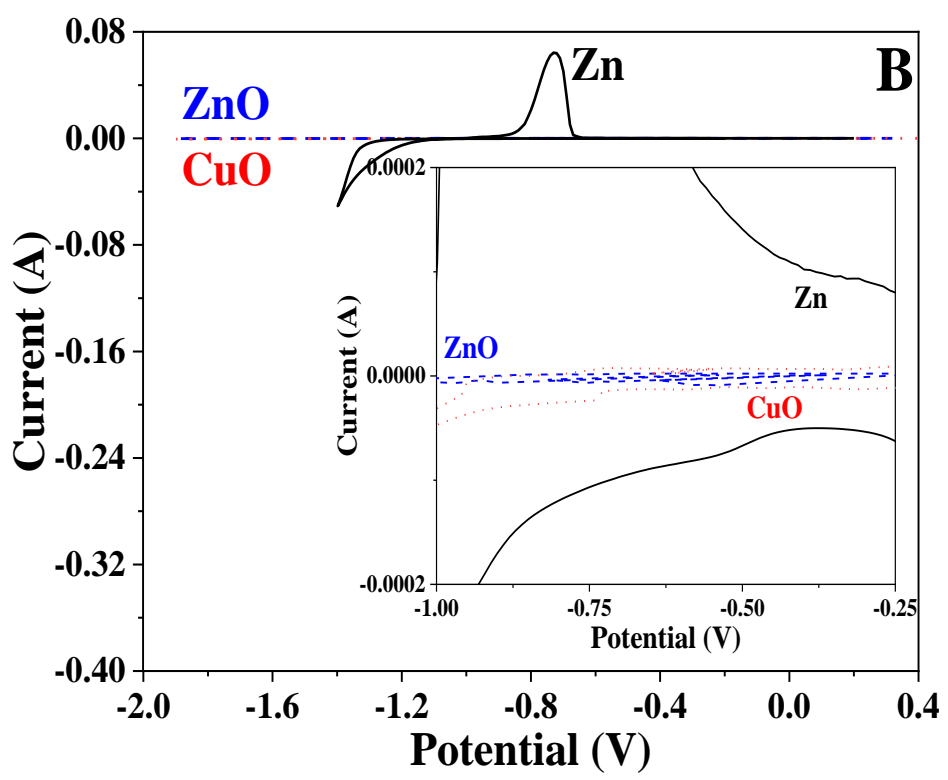

Figure 8. Cyclic voltammetry measurements of $\mathrm{ZnO} / \mathrm{Zn}, \mathrm{CuO} / \mathrm{Zn}$, and ordinary $\mathrm{Zn}$ : (A) Inset cathodic process; (B) Inset - anodic process

The anodic branches of both CVA curves confirm the presence of thin layers ( $\mathrm{ZnO}$ or $\mathrm{CuO}$, respectively), which are dissolved during the anodic polarization-Figure $8 \mathrm{~B}$ (inset).

\section{Conclusions}

The presented investigations demonstrate the possibility for stabilization of $\mathrm{ZnO}$ and $\mathrm{CuO}$ nanoparticles in their suspensions against aggregation (as mentioned above, the zeta-potential of the particles increase to about $50 \mathrm{mV}$ due to polyelectrolyte adsorption). The main idea was to realize a formation of positively charged, PEI-covered nanoparticles, which would be suitable for further electrophoretic deposition at appropriate $\mathrm{pH}$ values on the cathode (low-carbon steel substrate) as an underlayer.

Thereafter, an ordinary zinc coating is electrodeposited from a zinc sulfate electrolyte. The obtained hybrid coatings show general homogeneous surface morphology. The results confirm the $\mathrm{ZnO}$ or $\mathrm{CuO}$ incorporation in the hybrid coating, mainly near the interface between the steel and zinc coating.

The investigation of the corrosion resistance and electrochemical behavior of the obtained coatings with the same thickness as the ordinary zinc one shows better corrosion resistance and protective ability during a prolonged time interval as well as at conditions of external anodic polarization. Both hybrid coatings were found to improve the anticorrosion behavior of steel in a neutral model corrosion medium $(5 \% \mathrm{NaCl})$ compared with ordinary zinc coating.

Author Contributions: Conceptualization, T.R. and N.B. (Nikolai Boshkov); methodology, K.K. and N.B. (Neli Boshkova); formal analysis, K.K. and N.B. (Neli Boshkova); investigation, K.K. and N.B. (Neli Boshkova); writing_original draft preparation, K.K., N.B. (Neli Boshkova), T.R. and N.B. (Nikolai Boshkov); writing—review and editing, T.R. and N.B. (Nikolai Boshkov); visualization, T.R. and N.B. (Nikolai Boshkov); supervision, T.R. and N.B. (Nikolai Boshkov). All authors have read and agreed to the published version of the manuscript.

Funding: The project is funded by a project with Fund "Scientific Investigations", Bulgaria, KP06-China/4 (КП-06-Китай/4), entitled "Developing novel composite materials and their surface coatings for long-term anti-corrosion/biofouling applications".

Institutional Review Board Statement: Not applicable.

Informed Consent Statement: Not applicable. 


\section{Data Availability Statement: Not applicable.}

Acknowledgments: The authors express their gratitude to the project with the fund "Scientific Investigations", Bulgaria, КР-06-China/4 (КП-06-Китай/4), "Developing novel composite materials and their surface coatings for long-term anti-corrosion/biofouling applications".

Conflicts of Interest: The authors declare no conflict of interest.

\section{References}

1. Koch, G.; Brongers, M.; Thomson, N.; Virmani, Y.; Payer, J. Corrosion Cost and Preventive Strategies in the United States; NACE International: Houston, TX, USA, 2016.

2. Fragata, F.; Salai, R.; Amorin, C.; Almeida, E. Compatibility and incompatibility in anticorrosive painting: The particular case of maintenance painting. Prog. Org. Coat. 2006, 56, 257-268. [CrossRef]

3. Zheludkevich, M.L.; Shchukin, D.G.; Yasakau, K.A.; Moehwald, H.; Ferreira, M.G.S. Anticorrosion coatings with self-healing effect based on nanocontainers impregnated with corrosion inhibitor. Chem. Mater. 2007, 19, 402. [CrossRef]

4. Zheludkevich, M.L.; Tedim, J.; Ferreira, M.G.S. "Smart" coatings for active corrosion protection based on multi-functional micro and nanocontainers. Electrochim. Acta 2012, 82, 314-323. [CrossRef]

5. Praveen, B.M.; Venkatesha, T.V.; Arthoba Naik, Y. Corrosion studies of carbon nanotubes-Zn composite coating. Surf. Coat. Technol. 2007, 201, 5836-5842. [CrossRef]

6. Shajudheen, V.P.M.; Rani, K.A.; Kumar, V.S.; Maheswari, A.U.; Sivakumar, M.; Kumar, S.S. Optical and corrosion studies of spray pyrolysis coated titanium dioxide thin films. Adv. Sci. Lett. 2018, 24, 5836-5842. [CrossRef]

7. Radhakrishnan, S.; Siju, C.R.; Mahanta, D.; Patil, S. Conducting polyaniline-nano-TiO 2 composites for smart corrosion resistant coatings. Electrochim. Acta 2009, 54, 1249-1254. [CrossRef]

8. Shajudheen, V.P.M.; Kumar, S.S.; Kumar, V.S.; Maheswari, A.U.; Sivakumar, M.; Mohan, R.S. Enhancement of anticorrosion properties of stainless steel 304L using nanostructured ZnO thin films. AIMS Mater. Sci. 2018, 5, 932-944. [CrossRef]

9. Karbowniczek, J.; Cordero-Arias, L.; Virtanen, S.; Misra, S.K.; Valsami-Jones, E.; Rutkowski, B.; Górecki, K.; Bała, P.; CzyrskaFilemonowicz, A.; Boccaccini, A.R. Electrophoretic deposition of organic/inorganic composite coatings containing ZnO nanoparticles exhibitiong antibacterial properties. Mater. Sci. Eng. C 2017, 77, 780-789. [CrossRef] [PubMed]

10. Lin, Z.; Wang, Y.; Zhang, D.; Li, X. Corrosion resistance research of ZnO/polyelectrolyte composite film. Int. J. Electrochem. Sci. 2016, 11, 8512-8519. [CrossRef]

11. Cordero-Arias, L.; Cabanas-Polo, S.; Goudouri, O.M.; Misra, S.K.; Gilabert, J.; Valsami-Jones, E.; Sanchez, E.; Virtanen, S.; Boccaccini, A.R. Electrophoretic deposition of $\mathrm{ZnO} /$ alginate and $\mathrm{ZnO}$-bioactive glass/alginate composite coatings for antimicrobial applications. Mater. Sci. Eng. C 2015, 55, 137-144. [CrossRef]

12. Li, Y.; Wu, K.; Zhitomirsky, I. Electrodeposition of composite zinc oxide-chitosan films. Colloids Surf. A Physicochem. Eng. Asp. 2010, 356, 63-70. [CrossRef]

13. Šulčiūtè, A.; Ostachavičiūtè, S.; Valatka, E. Synthesis, structure and photoelectrochemical behaviour of ZnO coatings on AISI 304 type steel. Chemija 2017, 28, 85-92.

14. Verde, M.; Peiteado, M.; Caballero, A.C.; Villegas, M.; Ferrar, B. Electrophoretic deposition of transparent ZnO thin films from highly stabilized colloidal suspensions. J. Colloid Interface Sci. 2012, 373, 27-33. [CrossRef] [PubMed]

15. Sarkar, P.; Huang, X.; Nicholson, P.S. Zirconia/alumina functionally gradiented composites by electrophoretic deposition tech-niques. J. Am. Ceram. Soc. 1993, 76, 1055-1056. [CrossRef]

16. Dinamini, M.; Kamath, P.V.; Seshadri, R. Electrochemical deposition of $\mathrm{BaSO}_{4}$ coatings on stainless steel substrates. Chem. Mater. 2001, 13, 3981-3985. [CrossRef]

17. Dange, C.; Phan, T.N.T.; André, V.; Rieger, J.; Persello, J.; Foissy, A. Adsorption mechanism and dispersion efficiency of three anionic additives [poly(acrylic acid), poly(styrene sulfonate) and HEDP] on zinc oxide. J. Colloid Interface Sci. 2007, 315, 107-115. [CrossRef]

18. Fatehah, M.O.; Aziz, H.A.; Stoll, S. Stability of $\mathrm{ZnO}$ nanoparticles in solution. Influence of $\mathrm{pH}$, dissolution, aggregation and disaggregation effects. J. Colloid Sci. Biotechnol. 2014, 3, 75-84. [CrossRef]

19. Tang, F.; Uchikoshi, T.; Sakka, Y. Electrophoretic deposition behavior of aqueous nanosized zinc oxide suspensions. J. Am. Ceram. Soc. 2002, 85, 2161-2165. [CrossRef]

20. Olsen, S.M.; Pedersen, L.T.; Laursen, M.H.; Kiil, S.; Dam-Johansen, K. Enzyme-based antifouling coatings: A review. Biofouling 2007, 23, 369-383. [CrossRef]

21. Almeida, E.; Diamantino, T.C.; de Sousa, O. Marine paints: The particular case of antifouling paints. Prog. Org. Coat. 2007, 59, 2-20. [CrossRef]

22. Jia, Z.; Liu, Y.; Wang, Y.; Gong, Y.; Jin, P.; Suo, X.; Li, H. Flame spray fabrication of polyethylene-Cu composite coatings with enwrapped structures: A new route for constructing antifouling layers. Surf. Coat. Technol. 2017, 309, 872-879. [CrossRef]

23. He, X.; Abdoli, L.; Li, H. Participation of copper ions in formation of alginate conditioning layer: Evolved structure and regulated microbial adhesion. Colloids Surf. B Biointerfaces 2018, 162, 220-227. [CrossRef] [PubMed]

24. Piola, R.F.; Dafforn, K.; Johnston, E. The influence of antifouling practices on marine invasions. Biofouling 2009, $25,633-644$. [CrossRef] 
25. Vucko, M.J.; King, P.C.; Poole, A.J.; Hu, Y.; Jahedi, M.Z.; de Nys, R. Assessing the antifouling properties of cold-spray metal em-bedment using loading density gradients of metal particles. Biofouling 2014, 30, 651-666. [CrossRef]

26. Kruk, T.; Szczepanowicz, K.; Stefańska, J.; Socha, R.; Warszyński, P. Synthesis and antimicrobial activity of monodisperse copper nanoparticles. Colloids Surf. B Biointerfaces 2015, 128, 17-22. [CrossRef] [PubMed]

27. Rui, D.; Xiangbo, L.; Jia, W.; Likun, X. Electrochemical corrosion and mathematical model of cold spray $\mathrm{Cu}-\mathrm{Cu}{ }_{2} \mathrm{O}$ coating in $\mathrm{NaCl}$ solution-Part I: Tafel polarization region model. Int. J. Electrochem. Sci. 2013, 8, 5902-5924.

28. Aruoja, V.; Dubourguier, H.-C.; Kasemets, K.; Kahru, A. Toxicity of nanoparticles of $\mathrm{CuO}, \mathrm{ZnO}_{\text {and }} \mathrm{TiO}_{2}$ to microalgae Pseudokirchneriella subcapitata. Sci. Total. Environ. 2009, 407, 1461-1468. [CrossRef] [PubMed]

29. Son, J.; Vavra, J.; Forbes, V.E. Effects of water quality parameters on agglomeration and dissolution of copper oxide nanoparticles (CuO-NPs) using a central composite circumscribed design. Sci. Total Environ. 2015, 521, 183-190. [CrossRef]

30. Khan, R.; Inam, M.A.; Zam, S.Z.; Akram, M.; Shin, S.; Yeom, I.T. Coagulation and dissolution of CuO nanoparticles in the presence of dissolved organic matter under different $\mathrm{pH}$ values. Sustainability 2019, 11, 2825. [CrossRef]

31. Sousa, V.S.; Teixeira, M.R. Aggregation kinetics and surface charge of $\mathrm{CuO}$ nanoparticles: The influence of $\mathrm{pH}$, ionic strength and humic acids. Environ. Chem. 2013, 10, 313-322. [CrossRef]

32. Shehayeb, S.; Deschanels, X.; Lautru, J.; Ghannam, L.; Odorico, M.; Karamé, I.; Toquer, G. Thin polymeric CuO film from EPD designed for low temperature photothermal absorbers. Electrochim. Acta 2019, 305, 295-303. [CrossRef]

33. Wang, Y.; Deen, I.; Zhitomirsky, I. Electrophoretic deposition of polyacrylic acid and composite films containing nanotubes and oxide particles. J. Colloid Interface Sci. 2011, 362, 367-374. [CrossRef]

34. Kamburova, K.; Boshkova, N.; Boshkov, N.; Radeva, T. Composite coatings with polymeric modified ZnO nanoparticles and nanocontainers with inhibitor for corrosion protection of low carbon steel. Colloids Surf. A Physicochem. Eng. Asp. 2021, 609, 125741. [CrossRef]

35. Kamburova, K.; Boshkova, N.; Boshkov, N.; Atanassova, G.; Radeva, T. Hybrid zinc coatings for corrosion protection of steel using polyelectrolyte nanocontainers loaded with benzotriazole. Colloids Surf. A Physicochem. Eng. Asp. 2018, 559, 243-250. [CrossRef]

36. Boshkov, N.; Tsvetkova, N.; Petrov, P.; Koleva, D.; Petrov, K.; Avdeev, G.; Tsvetanov, C.; Raichevski, G.; Raicheff, R. Corrosion behavior and protective ability of $\mathrm{Zn}$ and $\mathrm{Zn}$-Co electrodeposits with embedded polymeric nanoparticles. Appl. Surf. Sci. 2008, 254, 5618-5625. [CrossRef]

37. Finšgar, M.; Fassbender, S.; Nicolini, F.; Milošev, I. Polyethyleneimine as a corrosion inhibitor for ASTM 420 stainless steel in near-neutral saline media. Corros. Sci. 2009, 51, 525-533. [CrossRef] 